\title{
Competitive Advantages of Labor-intensive Manufacturing Industry in China
}

\author{
Jiping WANG ${ }^{1, *}$ \\ ${ }^{1}$ School of Management, Wuhan Textile University, P.R., China \\ 1.wjp465@163.com
}

\begin{abstract}
Keywords: Labor-intensive Industry, Revealed Comparative Advantages, Error Correction Model. Abstract. We construct a model between labor costs and revealed comparative advantage index in Chinese manufacturing industry. Using annual data from 1995 to 2014, we found that the two series of labor costs and revealed comparative advantages index are non-stationary. They are in co-integration. The revealed comparative advantages index are from 1.66 to 2.01. The results showed that Chinese labor-intensive industry still maintained a comparative edge in the world, however it has a risk to decline.
\end{abstract}

\section{Introduction}

Revealed comparative advantages (RCA) index are frequently used as an index to evaluate the industrial competitive. The index can easily reveal the relation of export in the whole world. Then indicate the industrial or product competitive. Why the RCA in different industries varied? RCA of Labor-intensive industry may closely relate to the labor cost (LC), while capital-intensive industry may come from investment intensity. In China, some scholars insisted that RCA declined because of the sharp rising wages in the labor-intensive industry. Then the best way is to strongly develop capital-intensive industry instead of labor-intensive industry. While other researchers did not agree with it.

David Ricardo(1870) created the comparative advantage theory as against Adam Smith's absolute advantage theory. It has become the main method in analyzing the trade profit. A century later, Sweden economist Heckscher and Ohlin provided the dominant theory of factor endowment theory. Later, Haberler(1933), Wassily W. Leintief(1933), Lerner(1932) improved it. Posoner (1961) used Technology gap theory to explore the merit. Vernon(1966) discussed it by Product life cycle theory.

Paul Krugman(1972) created Scale economy and trade theory. Micheal Port raised the competitive strategies, national strategy and advantages of competition. Whereas Krugman reject that Port's view did not be applied in terms of nations, it only can be applied in firms. Hong(1977) argued the trap of comparative advantages. He insisted that the comparision of cost should be discussed within a country other than out of the country. Leintief 's mothod of input-output model was a good way. However the basic data of materials is hard to get. So the Balassa $(1965,1989)$ revealed comparative advantages index can be the reflection of trade advantages. Hausmann(2013) and Dai (2015) analyzed the CRA of primary sector, secondary sector and tertiary sector in China. However, above discussions did not reveal the positive relations between CRA and LC in dynamic ways.

Analysis of this paper is a comprehensive method of RCA and LC of in-depth theoretical single-equation model. It summarizes the scholars research between RCA and LC, and use error correction models( ECM) to explore the relationships positively.

The innovation of this paper is to use a longer time-series data quantitative analysis which improve the reliability and validity of the model, then revised and improved some of the conclusions of previous studies.

The paper was organized as follows, the second part was a theoretical overview of the relationship between the RCA and LC and data resources, the third part was the empirical analysis on Chinese RCA and LC, the fourth part draw conclusions. 


\section{Theoretical model of RCA and LC}

According to literatures, the RCA is

$$
R C A_{i j}=\frac{X_{i j} / \sum_{i}^{N} X_{i j}}{\sum_{j}^{N} X_{i j} / \sum_{i}^{M} \sum_{j}^{N} X_{i j}}
$$

$X_{i j}$ is the export of labor-intensive products within a country; $\sum_{i}^{N} X_{i j}$ is the total export of the country. $\sum_{j}^{N} X_{i j}$ is the export of labor-intensive products in the world. $\sum_{i}^{M} \sum_{j}^{N} X_{i j}$ whole world trade. This paper using ECM model is to analyze and to determine the correlation between RAC and LC

\section{Empirical Analysis of RCA and LC in China}

\section{Models Construction}

\section{Basic model}

First of all, we have established a single basic RCA and LC model

$$
\ln \left(R C A_{t}\right)=\alpha+\beta_{t} \ln \left(S L C_{t}\right)+u_{t} \quad t=1,2, \ldots, T
$$

RCA is the reveal competitive advantage index, $\mathrm{LC}$ is the labor cost in China.

\section{Data Collection and Selection}

The data were from UN Comtrade website, China National Bureau of Statistics and China National Customs. The type of products are goods and services. In this paper, we choose the goods trade data. The standards of goods are HS, SITC and BEC. We use SITC rev.3. For the rev.4. has a short period. The labor intensive product are 6th category and 8th category of the goods. The labor cost in China, we use the total salary of the work force divided by the number of employment.

\section{Model Analysis and testing}

Serial Correlation Test of the Model

After regression of model, we obtained the results:

$$
\begin{array}{r}
\ln (R C A)=0.962536-0.037330 \ln (L C) \\
\mathrm{t}=4.241939 \quad-1.645178
\end{array}
$$

\section{$\mathrm{R} 2=0.13712 \quad \operatorname{Prob}($ F-statistic $)=0.117283$ D.W=0.318653}

From the negative sign of $\ln (\mathrm{LC})$, we can understand that RCA will decline when the salary rises. It conformed with the experience. The intercept was positive revealed the RCA will be in some constant. The residuals of equation (3.2) are shown in Figure 1.

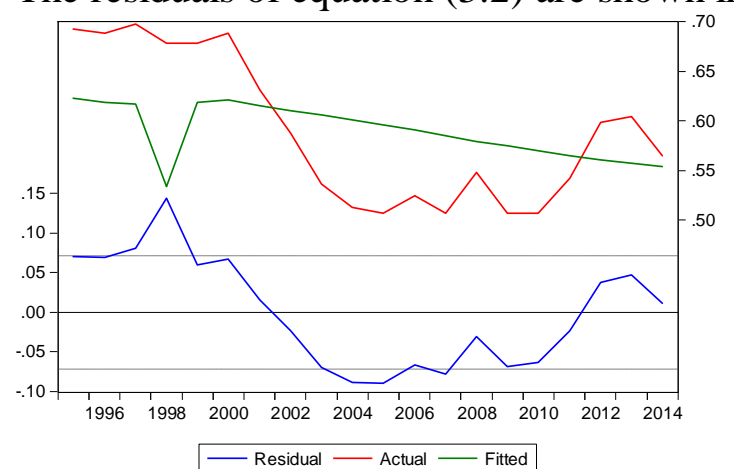

Fig 1. Model residual,actual and fitted picture

Since the model containing the intercept, D.W test cannot be used. We use Q and LM tests. LM test results are shown in Table 1. 
Table 1. LM test of model (3.2)

Breusch-Godfrey Serial Correlation LM Test:

\begin{tabular}{llll}
\hline \hline F-statistic & 18.45300 & Prob. $F(2,16)$ & 0.0001 \\
Obs ${ }^{\star}$ R-squared & 13.95154 & Prob. Chi-Square(2) & 0.0009 \\
\hline \hline
\end{tabular}

LM statistics showed that at the 5\% significance level it does not reject the null hypothesis which the residual series regression equation is serial correlation. So, the estimation results of the regression equation is invalid.

We then using Q test, test results are shown in Figure 2.

\begin{tabular}{|c|c|c|c|c|c|c|c|c|}
\hline \multicolumn{2}{|c|}{ Autocorrelation } & \multicolumn{2}{|c|}{ Partial Correlation } & & $A C$ & PAC & Q-Stat & Prob \\
\hline I & & 1 & & 1 & 0.813 & 0.813 & 15.297 & 0.000 \\
\hline 1 & $\square$ & & 1 & 2 & 0.631 & -0.086 & 25.041 & 0.000 \\
\hline I & $\square$ & $1 \square$ & 1 & 3 & 0.388 & -0.295 & 28.938 & 0.000 \\
\hline & $\overrightarrow{1} 1$ & $1 \square$ & 1 & 4 & 0.133 & -0.228 & 29.424 & 0.000 \\
\hline 10 & 1 & & 1 & 5 & -0.070 & -0.033 & 29.566 & 0.000 \\
\hline $1 \square$ & । & 1 & 1 & 6 & -0.255 & -0.133 & 31.615 & 0.000 \\
\hline$\square$ & । & 10 & I & 7 & -0.390 & -0.119 & 36.765 & 0.000 \\
\hline$\square$ & । & 1 & 1 & 8 & -0.449 & -0.002 & 44.157 & 0.000 \\
\hline 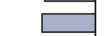 & । & 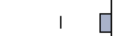 & 1 & 9 & -0.480 & -0.104 & 53.389 & 0.000 \\
\hline$\square$ & । & 1 & 1 & 10 & -0.390 & 0.168 & 60.080 & 0.000 \\
\hline $1 \square$ & 1 & 10 & I & 11 & -0.319 & -0.130 & 65.048 & 0.000 \\
\hline $1 \square$ & 1 & 10 & 1 & 12 & -0.227 & -0.094 & 67.889 & 0.000 \\
\hline
\end{tabular}

Fig. 2 The basic model of residual serial correlation diagram

As can be seen, autocorrelation and partial correlation are out of the scope of double standard variation. It is serial correlation. Also $\mathrm{P}$ values of $\mathrm{Q}$ statistic are more than 5\% which indicate that in $5 \%$ significance level, it does not reject the null hypothesis, the presence of residual series model is a serial correlation. When the test results do not reject the null hypothesis, level of significance, goodness of fit test and F statistics will not be trusted.

Unit Root Test on RCA and LC

In order to obtain intuitive understanding, we first draw charts of two variables trends which are Figure 3 and Figure 4.

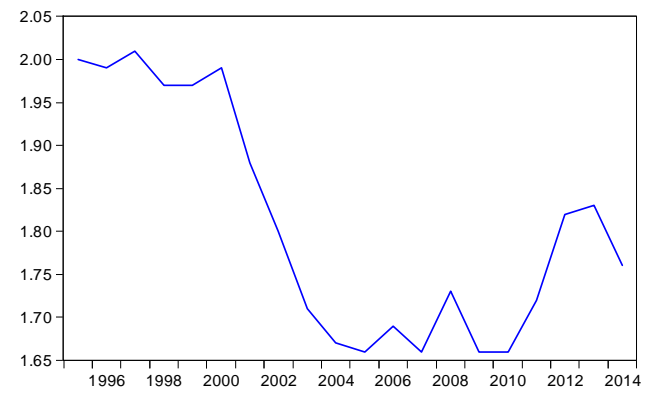

Fig 3. Trend of RCA from the year1995 to2014 in China

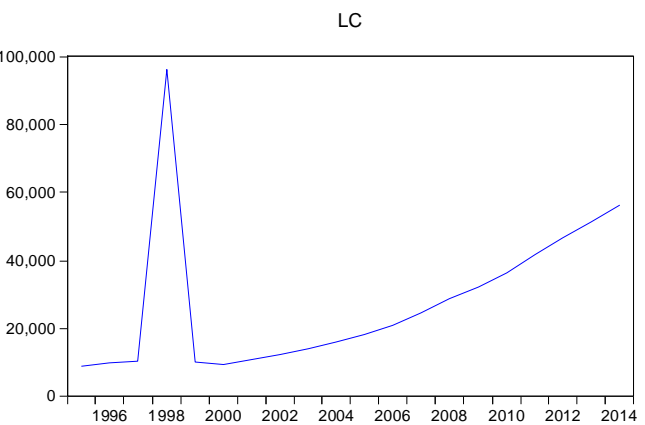

Fig 4. Trend of China's labor cost

The labor cost among the year of 1996-1999, the labor cost rise sharply, then decrease suddenly. We argued it is the reason of price reform in China. Another reason maybe the transition of labor market.

We judges that RCA has no clear trend. So, with unit root test, we have selected the intercept, no trend item unit root test. Analysis of results are shown in Table 2.

Table 2. ADF test of RCA

\begin{tabular}{lccc}
\hline \hline & t-Statistic & Prob. $^{*}$ \\
\hline \hline Augmented Dickey-Fuller test statistic & -1.447669 & 0.5373 \\
\hline Test critical values: & $1 \%$ level & -3.831511 & \\
& $5 \%$ level & -3.029970 & \\
& $10 \%$ level & -2.655194 & \\
\hline \hline
\end{tabular}

As can be seen, $\mathrm{P}=0.5373$, the test results showed, RCA serial data would accept the null hypothesis which is a non-stationary sequence. 
To make a first order difference of RCA sequence, then RAC choose a constant term and time trend, ADF test, test results are shown in Table 3.

Table 3. ADF test of RCA(-1)

\begin{tabular}{lccc}
\hline \hline & & t-Statistic & Prob. $^{*}$ \\
\hline \hline Augmented Dickey-Fuller test statistic & -3.051955 & 0.0489 \\
\hline Test critical values: & 1\% level & -3.857386 & \\
& $5 \%$ level & -3.040391 & \\
& $10 \%$ level & -2.660551 & \\
\hline
\end{tabular}

Test results show that the first order difference of sequence RCA at the 95\% significance level, reject the null hypothesis. The difference of sequence have a first order difference of stationary series, and $\mathrm{RCA} \sim \mathrm{I}(1)$.

Next, we determine the sequence of LC is not stable.

In the labor cost figures, we can observe that, from the years of 1995 to 2014 , China's laobur cost has a clear upward trend. When ADF test, select the constant term and contains time trend. LC's ADF test sequences are shown in Table 4.

Table 4. ADF test of LC

\begin{tabular}{lccc}
\hline \hline & t-Statistic & Prob. $^{*}$ \\
\hline \hline Augmented Dickey-Fuller test statistic & -2.258817 & 0.1944 \\
\hline Test critical values: & $1 \%$ level & -3.857386 & \\
& $5 \%$ level & -3.040391 & \\
& $10 \%$ level & -2.660551 & \\
\hline \hline
\end{tabular}

Test results show, LC sequence with almost the maximum value of $\mathrm{P} 0.194$, that is $19.4 \%$ significance level of acceptance of the null hypothesis that LC has a unit root. To make a first order difference of LC sequence, then LC choose a constant term and time trend, ADF test, test results are shown in Table 5.

\begin{tabular}{|c|c|c|c|}
\hline & & t-Statistic & Prob.* \\
\hline \multicolumn{2}{|c|}{ Augmented Dickey-Fuller test statistic } & -4.500511 & 0.0030 \\
\hline \multirow[t]{3}{*}{ Test critical values } & $1 \%$ level & -3.886751 & \\
\hline & $5 \%$ level & -3.052169 & \\
\hline & $10 \%$ level & -2.666593 & \\
\hline
\end{tabular}

Test results show that the first order difference of sequence LC at the 95\% significance level, reject the null hypothesis. The difference of sequence have a first order difference of stationary series, and $L C \sim I(1)$

Then we use another test, unit root test of Dickey-Fuller GLS, the results are the same.

RCA and LC's ECM Model

Because RCA is a AR(1) sequence, LC is also an AR(1) serials. The two variable series do have the same integer order, we can use the co-integration test. After the test, we found that RCA and LC serials are co-integration.

We establish RCA and LC error correction model (ECM)

Firstly establish long-term equilibrium equation using the data of the year 1995 to 2014

$\ln (R C A)=k_{0}+k_{1} \ln (L C)+u_{t} \quad t=1,2, \ldots, T$

So let residual series $e c m_{t}=\hat{u}_{t}$, as the error correction term, the establishment of the following error correction model is

$\Delta \ln (R C A)=\beta_{0}+\alpha e c m_{t-1}+\Delta \beta_{1} \ln (L C)+\varepsilon_{t}$

After the estimation, the result of equation (3.4) is

$\Delta \ln (R C A)=0.345196 \Delta \ln (R C A(-1))-0.012919 \ln (L C)-0.004380 \ln (L C(-1))+0.162545 e m_{t-1}$ 
By measurement result ECM regression equation, we find that RCA affected their development in the extent of $16.25 \%$. LC is some weak. ECM reflects the size of the coefficient of deviation from the long-run equilibrium of readjustment. From 0.16 coefficient estimates we can see, when short-term fluctuations deviate from the long-term equilibrium, it will adjust the intensity of 0.16 , make non-equilibrium state back to equilibrium.

\section{Conclusions}

Inspecting on Chinese revealed comparative advantage and labor cost, the results are:

(1) Chinese revealed comparative advantage is an AR(1) sequence, and the labor cost is also a AR(1) non-stationary sequence.

(2) After construct ECM model, we found that the two variables are co-integration.

(3) When the short-term fluctuations deviate from the long-run equilibrium, the power of adjustment of the labor cost will be 0.16 , and the level of revealed comparative advantage will be back to equilibrium very slightly.

\section{Acknowledgement}

This research was financially supported by the Science Foundation of Ministry of Education of China(Grant No.11YJA630122 ); Wuhan Textile University Research Team on Textile Industry Development and Innovation in China (Grant No.201316-27 ).

\section{References}

[1] Thomas L. Vollrath, A theoretical evaluation of alternative trade intensity measures of revealed comparative advantage, Review of World Economy, Volume 127, Issue 2, June 1991, pp 265-280

[2]Bela Balassa, Trade Liberalisation and "Revealed" Comparative Advantage1,The Manchester School, Volume 33, Issue 2, May 1965, pages 99-123

[3] Tamberi, Revealed' Comparative Advantage Revisited: An Analysis of Relative Export Shares of the Industrial Countries, 1953-1971, The Manchester School, Volume 45, Issue 4, December 1977 ,PP. 327-344,

[4] Harry P. Bowen, On the theoretical interpretation of indices of trade intensity and revealed comparative advantage, Weltwirtschaftliches Archiv, June 1980, Volume 116, Issue 2, pp 315-321

[5] Belay Seyoum, Revealed comparative advantage and competitiveness in services: A study with special emphasis on developing Countries, Journal of Economic Studies, Volume 34, Issue 5,1974

[6] Štefan Bojnec ,Trade and Revealed Comparative Advantage Measures: Regional and Central and East European Agricultural Trade, Eastern European Economics ,Volume 39, Issue 2, 2001

[7] V Serin, A Civan, Revealed comparative advantage and competitiveness: A case study for Turkey towards the EU, Journal of Economic and Social Research, 2008

[8] Jaimin Lee, Comparative advantage in manufacturing as a determinant of industrialization: The Korean case, World Development, Volume 23, Issue 7, July 1995, Pages 1195-1214

[9] Taylor \& Francis ,, Trade and revealed comparative advantage measures: regional and central and east European agricultural trade, Eastern European Economics, 2001

[10] R Yu, J Cai, PS Leung, The normalized revealed comparative advantage index, The Annals of Regional Science, 2009

[11] Xiang Wei, International Comparative of Chinese manufacturing sector, China Industrial Economics, Volume 322, Issue 1,Jan,2015 (in Chinese) 